Baptist Health South Florida

Scholarly Commons @ Baptist Health South Florida

$11-2021$

\title{
Long-term Patient-Reported Outcome Measures Following \\ Particulated Juvenile Allograft Cartilage Implantation for Treatment of Difficult Osteochondral Lesions of the Talus
}

Cary Chapman

Baptist Health Orthopedic Institute, carych@baptisthealth.net

Follow this and additional works at: https://scholarlycommons.baptisthealth.net/se-all-publications

\section{Citation}

Foot and Ankle International (2021) 42(11):1399-1409

This Article -- Open Access is brought to you for free and open access by Scholarly Commons @ Baptist Health South Florida. It has been accepted for inclusion in All Publications by an authorized administrator of Scholarly Commons @ Baptist Health South Florida. For more information, please contact Carrief@baptisthealth.net. 
Long-term Patient-Reported Outcome Measures Following Particulated Juvenile Allograft Cartilage Implantation for Treatment of Difficult Osteochondral Lesions of the Talus $\stackrel{\text { Unfo }}{\mathcal{C}}$

\author{
Joseph Manzi, BS', Artine Arzani, BS' (D), Mathew J. Hamula, MD², \\ Kshitij Manchanda, MD ${ }^{3}$ DD, Dinesh Dhanaraj, MD, MSPH ${ }^{4}$, \\ and Cary B. Chapman, MD ${ }^{3}$
}

\begin{abstract}
Background: Conventional methods are not suitable for difficult to treat osteochondral lesions of the talus (OCLTs). The role of particulated juvenile allograft articular cartilage implantation is not well elucidated for long-term patient outcomes. Methods: Thirteen patients with difficult-to-treat OCLTs underwent arthroscopy-assisted implantation of particulated juvenile articular cartilage graft into defects from 2010 to 2012 by the same surgeon. "Difficult to treat" was defined as having at least 3 of the following features or 2 if both variables described lesion characteristics: (I) lesions size of $107 \mathrm{~mm}^{2}$ or greater, (2) shoulder lesions, (3) patients who failed microfracture, (4) patient aged $\geq 40$ years, or (5) patient body mass index $(\mathrm{BMI})>25$. Patients were evaluated using physical examination, patient interviews, and outcome score measures. Patients had follow-up at 2 years, 4 years, and between 6 and 10 years at their most recent follow-up. Differences in functional outcome scores were compared before and after surgery.

Results: Patients (age: $46.5 \pm$ I I.8 years, BMI: $28.5 \pm 6.1$ ) had, on average, most recent follow-up of 8.0 years (range 72 I I 3 months). Average visual analog scale for pain score decreased for patients by 3.9 points $(95 \%$ confidence interval [Cl] 2. 18-5.60), when compared to preoperative assessment. Foot and Ankle Ability Measure (FAAM) Activities of Daily Living (ADL) and Sports subscale scores also improved from 46.5 to 80.9 (95\% Cl 21.35-47.43), and from 18.8 to 57.9 (95\% Cl 21.05-57.10), respectively. Short Form-36 Health Survey physical component scores showed significant improvement by an average of 45.5 points $(95 \% \mathrm{Cl} 32.42-58.50)$. American Orthopaedic Foot \& Ankle Society Ankle-Hindfoot Scale scores improved from 55.2 to 80.3 ( $95 \% \mathrm{Cl} 12.459-37.74 \mathrm{I})$.

Conclusion: These results demonstrate positive patient-reported long-term outcomes for a cohort of patients with difficult OCLTs, followed over the course of 6-10 years after treatment with arthroscopy-assisted particulated juvenile articular cartilage implantation.

Level of Evidence: Level II, prospective cohort study.
\end{abstract}

Keywords: talus, osteochondral defects, talar osteochondral lesions, microfracture, juvenile articular cartilage implantation

\section{Introduction}

Ankle injuries are one of the most common reasons to seek medical attention, with an estimated 1 million ankle injuries occurring per year. ${ }^{5,28}$ Osteochondral lesions of the talus (OCLTs) have been reported to occur at an incidence of $0.1 \%$ of all talus fractures, though in a population of military recruits analyzed over the course of 10 years, a more frequent occurrence was noted at 27 OCLTs per 100000
'Weill Cornell Medical College, New York, NY, USA ${ }^{2}$ NYU Langone Orthopedic Hospital, New York, NY, USA

${ }^{3}$ Miami Orthopedics \& Sports Medicine Institute, Coral Gables, FL, USA ${ }^{4}$ Penn Medicine Princeton Medical Center, Plainsboro Township, NJ, USA

\section{Corresponding Author:}

Cary B. Chapman, MD, Miami Orthopedics \& Sports Medicine Institute, I I50 Campo Sano Ave Ist Floor, Coral Gables, FL 33 I46, USA.

Email: CaryCh@baptisthealth.net 
persons per year. ${ }^{34,42}$ Traumatic ankle injuries are the major source of osteochondral lesions or defects in the talus, with up to $50 \%$ of traumatic ankle sprains and fractures associated with talar lesions ${ }^{47}$ Repetitive microtrauma, degenerative joint arthropathy, and metabolic disarrangements contributing to osteonecrosis are all secondary etiologies of OCLTs described. ${ }^{15,31,35,46,58}$

Distal fibular fractures, complete deltoid ligament ruptures, and chronic lateral ligament instability have the highest concomitant association with talar lesions (range, $55 \%-100 \%) .{ }^{27}$ These articular cartilage injuries, as distinct pathologies or summated, can have a significant impact on occupation as well as activities of daily living, with a range of presentations from asymptomatic to chronic pain and disability. ${ }^{25,43,48,51}$

Initial operative management typically consists of arthroscopic removal of loose bodies and bone marrow stimulation (BMS) techniques such as debridement, microfracture, abrasion chondroplasty, curettage, and antegrade or retrograde drilling, having demonstrated overall positive results, particularly for smaller lesions. ${ }^{37,49,55}$ However, it is widely accepted that this method leads to fibrocartilage with predominantly type 1 collagen that can lead to unpredictable histologic structure, wear properties, and ultimately, unpredictable longevity compared with normal hyaline cartilage. ${ }^{22,37}$

Larger lesions or those with underlying subchondral bone involvement, in the form of cystic changes or sclerosis, require either osteochondral allograft or autologous chondrocyte implantation. ${ }^{23,36,40}$ Traditionally, the minimum lesion area for these procedures was set at $150 \mathrm{~mm}^{2}$ given the effectiveness of BMS techniques for smaller lesions; however, more recent studies have demonstrated these techniques may in fact be useful for lesion sizes as small as 107 $\mathrm{mm}^{2}{ }^{12,44,53,59}$ Beyond size, other risk factors that should be considered when choosing cartilage restoration over BMS include: medial lesions, ${ }^{57}$ shoulder lesions, $, 16,24,29,57$ presence of a cyst, ${ }^{16,29}$ ankle instability, ${ }^{33}$ repeat surgery, ${ }^{16}$ patient age greater than 40 years, ${ }^{18,57}$ and body mass index. ${ }^{18}$

Osteochondral autograft transfer system has been accepted as the primary method of treatment for these more difficult defects; however, complications such as residual knee pain from the graft site, a multiday procedure, and the necessity for a malleolar osteotomy have made this technique not devoid of its own issues. ${ }^{32,38,50}$ Donor site harvesting in mosaicplasty has noted as high as a $19.6 \%$ rate of morbidity of the donor site for knee-ankle, more than triple that of knee-knee. ${ }^{4,7}$ Furthermore, a systematic review conducted by Bull et $\mathrm{al}^{13}$ observed for patients who had a biplane medial malleolar chevron osteotomy, $30 \%$ had measurable incongruence at the joint line whereas $6 \%$ had nonunion observed by radiograph. These complication rates are difficult to neglect. Advocating for an alternative intervention devoid of these pitfalls is merited.
One option to consider is allograft techniques, which can be performed entirely arthroscopically, in the course of a single operation, and do not require a donor site. ${ }^{52}$ Particulated juvenile articular cartilage - a prepackaged articular cartilage allograft from young donors (ages less than 13 years) with viable chondrocytes and hyaline cartilage - has demonstrated good results in microfractures, refractory lesions, as well as larger lesions unlikely to respond to BMS techniques. ${ }^{8,14,17,45}$ Short to midterm follow-up of patients with particulated juvenile articular cartilage treatment has shown improvement in ankle pain and disability as well as MRI data suggesting that defect filling is possible and persists for at least 2 years. ${ }^{17,19,21,26,30}$ Several of these reports concluded that this allograft had significant potential but that further trials needed to be conducted to fully elucidate its uses and indications. Similarly, no institution has published mid- to long-term follow-up results for a population treated by particulated juvenile articular cartilage allograft transplantation.

Therefore, the purpose of the current study was to evaluate the long-term quality of life metrics of patients treated with particulated juvenile allograft cartilage implantation for difficult to treat OCLTs. The authors hypothesize a statistically significant improvement in patient self-assessment metrics of ankle mobility, degree of pain, and functional capability after arthroscopy-assisted implantation of particulated juvenile articular cartilage graft when compared to preoperative scores.

\section{Methods}

\section{Patient Population, Study Selection, and Correspondence}

Following approval by our institutional review board, a total of 15 patients were included in the study considered as having a difficult to treat OCLT bone. "Difficult to treat" was defined as having at least 3 of the following features or 2 if both described lesion characteristics specifically: (1) lesions size of $107 \mathrm{~mm}^{2}$ or greater (measured arthroscopically), (2) shoulder lesions, (3) patients who failed microfracture, (4) patient age $\geq 40$ years, or (5) patient body mass index $>25$. These variables were selected based on prior literature suggesting each as (1) a risk factor for worsening lesion progression or (2) a poor prognosticator for improvement after operative intervention.,16,18,24,29,57 Evaluation before surgery included physical examination, patient interviews, and patient-reported outcome scores (PROMs), including visual analog scale for pain (maximum score: 10), Short Form-36 Health Survey physical and mental component summaries (SF-36 PCS and MCS, respectively; maximum score: 100), Foot and Ankle Ability Measure (FAAM) with Activities of Daily Living (ADL, maximum score: 100) and Sports subscales (maximum score: 100), and 


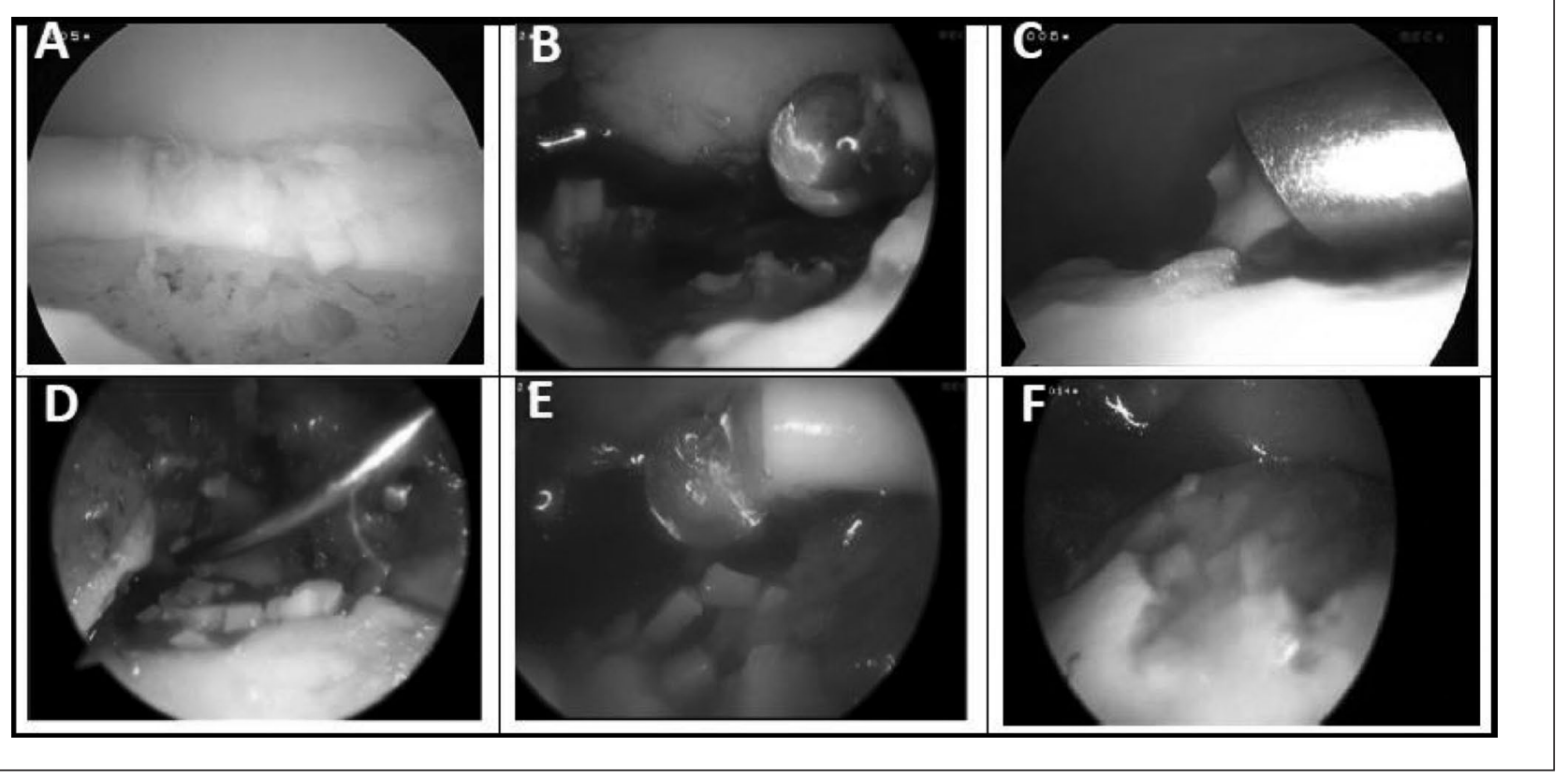

Figure I. Arthroscopic particulated juvenile cartilage allograft implantation. (A) Osteochondral lesion debrided to a stable border. (B) Fibrin glue placed at the base of the lesion after the fluid turned off and the area dried. (C) Graft administered onto the lesion. (D) Graft contoured into the lesion. (E) Additional layer of fibrin glue added to cover the graft. (F) Final lesion filled with the graft.

American Orthopaedic Foot \& Ankle Society (AOFAS) Ankle-Hindfoot Scale (maximum score: 100).

After having completed preoperative score assessment reports, these patients underwent arthroscopic implantation of particulated juvenile articular cartilage allograft tissue (DeNovo NT; Zimmer, Warsaw, IN) by the senior author (C.C.) between November 2010 and May 2012. OCLTs were further characterized intraoperatively by location as well as shoulder lesions. Patients with (1) arthroscopic lesion measurements of at least $107 \mathrm{~mm}^{2}$ or (2) a failed previous surgery for a microfracture were included in the final analysis.

\section{Operative Technique}

The patient is positioned supine. After induction of general anesthesia, the ankle is placed in an ankle distractor. The procedure begins with a diagnostic ankle arthroscopy. The location and size of the defect is noted, and any concomitant pathologies are addressed. All transplantations were performed arthroscopically without the use of a malleolar osteotomy. In order to maximize visibility and accessibility, the ankle is ranged and portal placement may be re-evaluated and repositioned accordingly. Lesion size was measured intraoperatively by the attending surgeon before proceeding. A probe with graduations every $1.0 \mathrm{~mm}$ was used to measure the lesion at its widest point in 2 planes under direct arthroscopic visualization. The remainder of the procedure is similar to the techniques described by Kruse et al $^{30}$ and Cerrato et al. ${ }^{14}$
With inflow of water suspended and the lesion appearing dried, a thin layer of Baxter TISSEEL fibrin glue (Deerfield, IL) is delivered with a syringe into the base of the lesion. The particulated juvenile articular cartilage is loaded retrograde into an ankle arthroscope canula on the back table. The graft is provided as particulated pieces, each measuring approximately $1 \mathrm{~mm}^{3}$, suspended in a preservation solution. Each package includes enough to cover a defect measuring $250 \mathrm{~mm}^{2}$. Multiple packages may be used for larger lesions.

The allograft is then placed in the lesion aiming to fill the defect to the level of the surrounding articular cartilage by using the arthroscope cannula trochar to carefully push the allograft into the defect. Next, a Freer Elevator is used to impact the graft to seat the particles flush with the surrounding native articular cartilage. Another layer of fibrin glue is delivered over the graft with 5 minutes given to dry. The portals are closed in a standard fashion. For patients with cystic OCD, the lesion was debrided to down to bleeding bone, and/or multiple channels were made in the base with a small microfracture pick. Bone graft from the calcaneus was used to fill the defect up to the adjacent subchondral bone, delivering it in a similar manner as described for the allograft. A thin layer of fibrin glue was then placed over the bone graft and the allograft cartilage was placed over that. The steps of particulated juvenile cartilage allograft implantation described here are pictorially depicted in Figure 1.

In the case of an uncontained lesion, there was typically a small rim of medial talar cartilage and subchondral bone that held some of the bone graft in place. A freer elevator 
was then used to contour the shape of the "corner" of the talus as best as possible. The allograft cartilage was then placed only on the superior surface of the talar dome.

Postoperatively, the patient is initially placed in a short leg splint and kept nonweightbearing for a total of 4 weeks. The patient is transitioned to a removable CAM boot at 2 weeks and is started on active and passive range of motion exercises, progressing to weightbearing as tolerated between 4 and 8 weeks. At 8 weeks, the patient is allowed to begin strength exercises and light activity, weaning off boot as tolerated. Return to sport or more strenuous activity is allowed as tolerated after 4-6 months.

\section{Clinical Evaluation and Data Collection}

Study participants were evaluated prospectively at 6 weeks, 12 weeks, 6 months, and at 2 years, 4 years, and 8 years with the same evaluation metrics mentioned in preoperative patient recruitment. Only evaluations collected at 2, 4, and 8 years after surgery were used in this analysis.

\section{Statistical Analysis}

This study enrolled consecutive patients undergoing particulated juvenile articular cartilage implantation by a single surgeon. Therefore, statistical power was not considered during subject enrollment. The confidence interval (CI) for 2 independent samples was used to compare mean outcome scores, with significance set at a CI of $95 \%$ with minimum range greater than 1. For comparison of patient outcome scores between postoperative follow-up dates, an analysis of variance was performed with post hoc analysis of 2-sample mean $t$ test if significance was derived. Alpha value was set at 0.05 for significance. The minimum clinically important difference (MCID) in scores was determined as the preoperative SD for each PROM utilized. The MCID is defined as "a statistical model that attempts to define the smallest change in a treatment outcome that a patient would identify as important." Although several methodologies for calculating the MCID have been utilized, ${ }^{54}$ the authors chose a higher threshold of a full rather than $0.5 \mathrm{SD}$ given the small sample size and likely nonparametric distribution of this study's cohort. All data were analyzed using SPSS software (version 20; IBM, Armonk, NY), Microsoft Excel (Microsoft Corporation, Redmond, WA), and Stata, version 16.1 (College Station, TX). Graphical depictions were created with Prism version 8.4 (GraphPad Software Inc, San Diego, CA).

\section{Results}

\section{Patient Demographics}

Two patients were ultimately excluded because of inadequate follow-up or no correspondence at all. The most recent follow-up for all patients averaged to $97.8 \pm 26.6$ months (range, 72-120 months). The average age at the time of surgery was $46.5 \pm 11.8$ years (range, $18-61$ years), with a maleto-female ratio of 8:5. The average body mass index was 28.5 \pm 6.1 (range, 20.6-36.9). The majority of patients reported a preceding traumatic injury to the ankle $(n=10,76.9 \%)$.

The mean lesion size measured on arthroscopy for all patients was $151 \pm 53 \mathrm{~mm}^{2}$ (range: $70-260 \mathrm{~mm}^{2}$ ), whereas the average lesion size for patients who had not undergone previous surgery was $155 \pm 38 \mathrm{~mm}^{2}$ (range: $120-216 \mathrm{~mm}^{2}$ ). Four patients $(30.8 \%)$ had undergone a previous surgery for microfracture of the lesion of interest with persistent or recurrent symptoms. Six $(46.2 \%)$ participants required an additional procedure at the time of implantation, in particular, bone grafts. Patient demographics, operative histories, and OCLT descriptions are listed in Table 1.

\section{Functional Outcome Scores}

The average visual analog scale for pain score decreased for patients by $3.9 \pm 2.8$ points (95\% CI $2.18-5.60)$, when compared to preoperative assessment. FAAM ADL and Sports scores also showed improvement by $34.4 \pm 21.8(95 \% \mathrm{CI}$ 21.35-47.43) and 39.0 \pm 20.7 (95\% CI 21.05-57.10), respectively. SF-36 physical component summary scores showed improvement by an average of $45.5 \pm 20.7$ points (95\% CI 32.42-58.50), whereas mental component scores improved by $26.0 \pm 21.9$ points (95\% CI 12.47-39.53). Average preoperative AOFAS score improved by $25.1 \pm$ 17.2 (95\% CI 12.44-37.72).

Between postoperative evaluation dates, there was no significant difference in patient-centered survey scores using the numbers available, except for SF-36 PCS between the 2-and 4-year and the 2-and 8-year follow-up (2-year $=50.5$ vs 4-year $=86.7,8$-year $=81.2 ; P$ value $<.001$ for both) and SF-36 MCS between 2- and 4-year and the 2 - and 8-year follow-up (2-year $=43.7$ vs 4 -year $=85.0,8$-year $=78.9 ; P$ value $<.001$ for both). These results are summarized in Table 2 , with patients with lesions greater than $150 \mathrm{~mm}^{2}$ demonstrating comparable results. Averaged patient functional outcome scores depicted over time is shown in Figure 2.

The MCID was achieved by $11(84.6 \%)$ patients for visual analog scale score, 11 (84.6\%) patients for FAAM ADL score, $13(100 \%)$ patients for FAAM Sports score, 12 (92.3\%) patients for AOFAS score, 12 (92.3\%) patients for SF-36 PCS score, and 8 (61.5\%) patients for SF-36 MCS. All but 2 patients achieved the MCID for the majority of PROMs (Table 1).

\section{Complications}

There were no intraoperative or perioperative complications observed. A postoperative MRI at 2-year follow-up for 1 patient demonstrated integration of bone graft with some hypertrophy of the allograft cartilage as shown in Figure 3. 


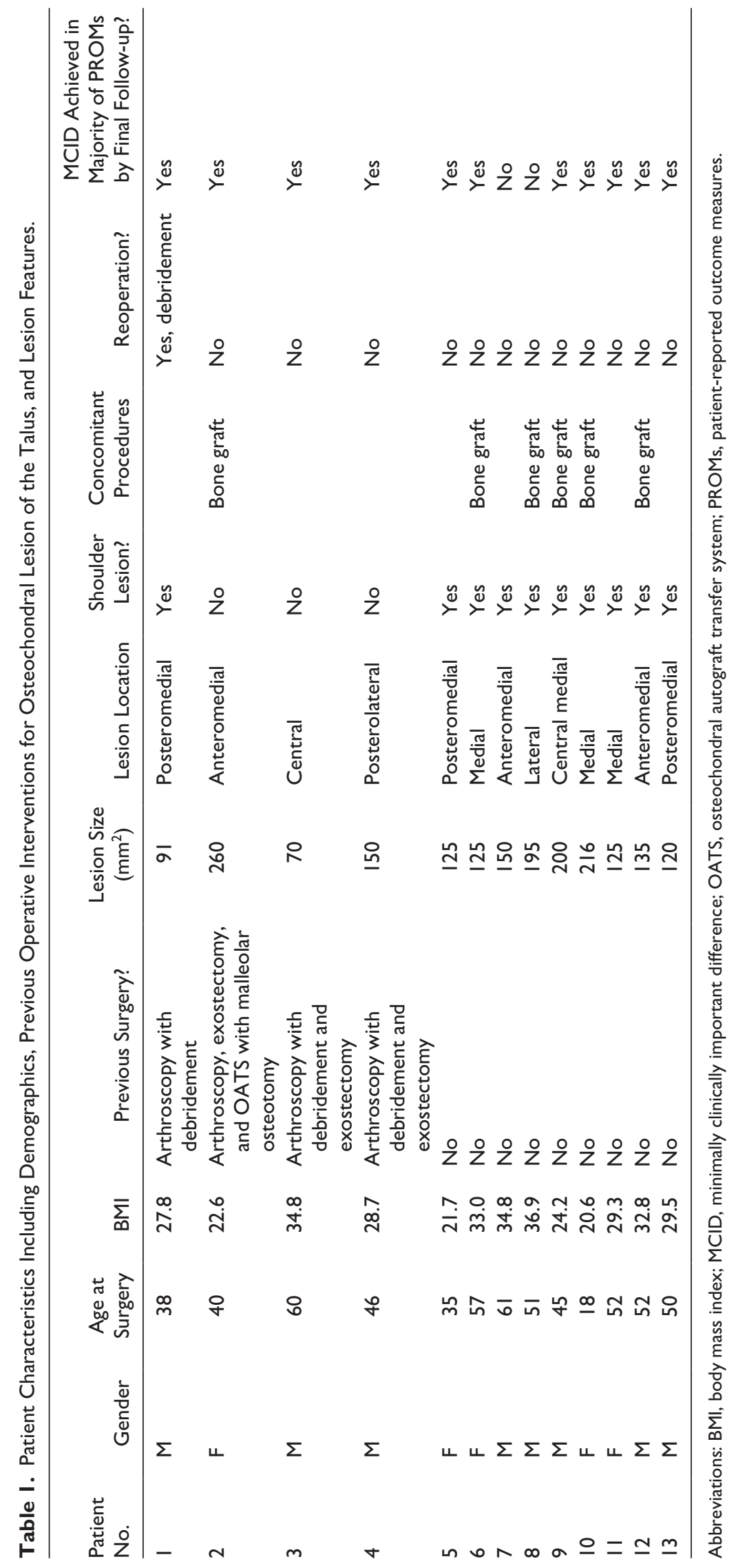


Table 2. Comparison of Preoperative and Latest Follow-up Functional Outcome Scores for Patients With Osteochondral Lesions of the Talus.

\begin{tabular}{|c|c|c|c|c|c|c|c|c|c|c|c|c|}
\hline \multirow[b]{2}{*}{$\begin{array}{l}\text { Patient } \\
\text { No. }\end{array}$} & \multicolumn{2}{|c|}{ VAS } & \multicolumn{2}{|c|}{ FAAM ADL } & \multicolumn{2}{|c|}{ FAAM Sports } & \multicolumn{2}{|c|}{ AOFAS } & \multicolumn{2}{|c|}{ SF-36 PCS } & \multicolumn{2}{|c|}{ SF-36 MCS } \\
\hline & Preop. & $\begin{array}{l}\text { Latest } \\
\text { Follow-up }\end{array}$ & Preop. & $\begin{array}{c}\text { Latest } \\
\text { Follow-up }\end{array}$ & Preop. & $\begin{array}{l}\text { Latest } \\
\text { Follow-up }\end{array}$ & Preop. & $\begin{array}{l}\text { Latest } \\
\text { Follow-up }\end{array}$ & Preop. & $\begin{array}{l}\text { Latest } \\
\text { Follow-up }\end{array}$ & Preop. & $\begin{array}{l}\text { Latest } \\
\text { Follow-up }\end{array}$ \\
\hline I & 6 & 0 & 65 & 98 & 46 & 75 & 67 & 93 & 43.7 & 95 & 30.4 & 84 \\
\hline 2 & 7 & 3 & 35 & 67 & 11 & 32 & 41 & 60 & 24.3 & 75.0 & 68.2 & 84 \\
\hline 3 & 6 & I & 39 & 92 & 25 & 89 & 70 & 100 & 32.6 & 95.0 & 47.2 & 92 \\
\hline 4 & 8.5 & 4 & 44.0 & 82 & 7.1 & 57 & 36.0 & 72 & 25.0 & 90 & 65.6 & 92 \\
\hline 5 & 5 & 2 & 84 & 95 & 35 & 90 & 67 & 95 & 38.7 & 100 & 56.3 & 60 \\
\hline 6 & 5 & 2 & 45 & 71 & 29 & 61 & 42 & 82 & 33.9 & 80 & 54.4 & 80 \\
\hline 7 & 6 & 8 & 49 & 62 & 18 & 39 & 53 & 64 & 32.7 & 30 & 59.4 & 64 \\
\hline 8 & 7 & 3 & 24 & 74 & 4 & 18.0 & 36 & 67 & 27.6 & 55 & 37.6 & 88 \\
\hline 9 & 10 & 6 & 62 & 46 & 7 & 25 & 67 & 54 & 36.9 & 60 & 50.4 & 92 \\
\hline 10 & 10 & I & 48 & 98 & 25 & 78 & 51 & 100 & 50 & 100 & 88 & 72 \\
\hline II & 8 & I & 36 & 100 & 29 & 100 & 70 & 100 & 30 & 100 & 92 & 100 \\
\hline 12 & 6 & 5 & 37 & 79 & 4 & 21 & 77 & 77 & 35.7 & 65 & 32.4 & 60 \\
\hline 13 & 4 & 2 & 36 & 87 & 4 & 67 & 41 & 80 & 23 & 80 & 36.1 & 88 \\
\hline $\begin{array}{l}\text { Mean } \\
(\mathrm{SD})\end{array}$ & $\begin{array}{c}6.8 \\
(2.2)\end{array}$ & $\begin{array}{c}1.9 \\
(1.6)^{*}\end{array}$ & $\begin{array}{c}46.5 \\
(15.8)\end{array}$ & $\begin{array}{c}80.9 \\
(16.4)^{*}\end{array}$ & $\begin{array}{c}18.8 \\
(13.8)\end{array}$ & $\begin{array}{c}57.9 \\
(28.3)^{*}\end{array}$ & $\begin{array}{c}55.2 \\
(14.9)\end{array}$ & $\begin{array}{c}80.3 \\
(16.3)^{*}\end{array}$ & $\begin{array}{l}33.4 \\
(7.8)\end{array}$ & $\begin{array}{c}78.9 \\
(21.4)^{*}\end{array}$ & $\begin{array}{c}55.2 \\
(19.6)\end{array}$ & $\begin{array}{c}81.2 \\
(13.2)^{*}\end{array}$ \\
\hline
\end{tabular}

Abbreviations: ADL, activities of daily living; AOFAS, American Orthopaedic Foot \& Ankle Society; FAAM, Foot and Ankle Ability Measure; MCS, mental composite summary; PCS, physical composite summary; Preop., preoperative; SF-36, Short Form-36 Health Survey; VAS, visual analog scale. "Mean scores (SD) between preoperative and latest follow-up showed statistically significant difference $(95 \%$ confidence interval does not contain the value I).

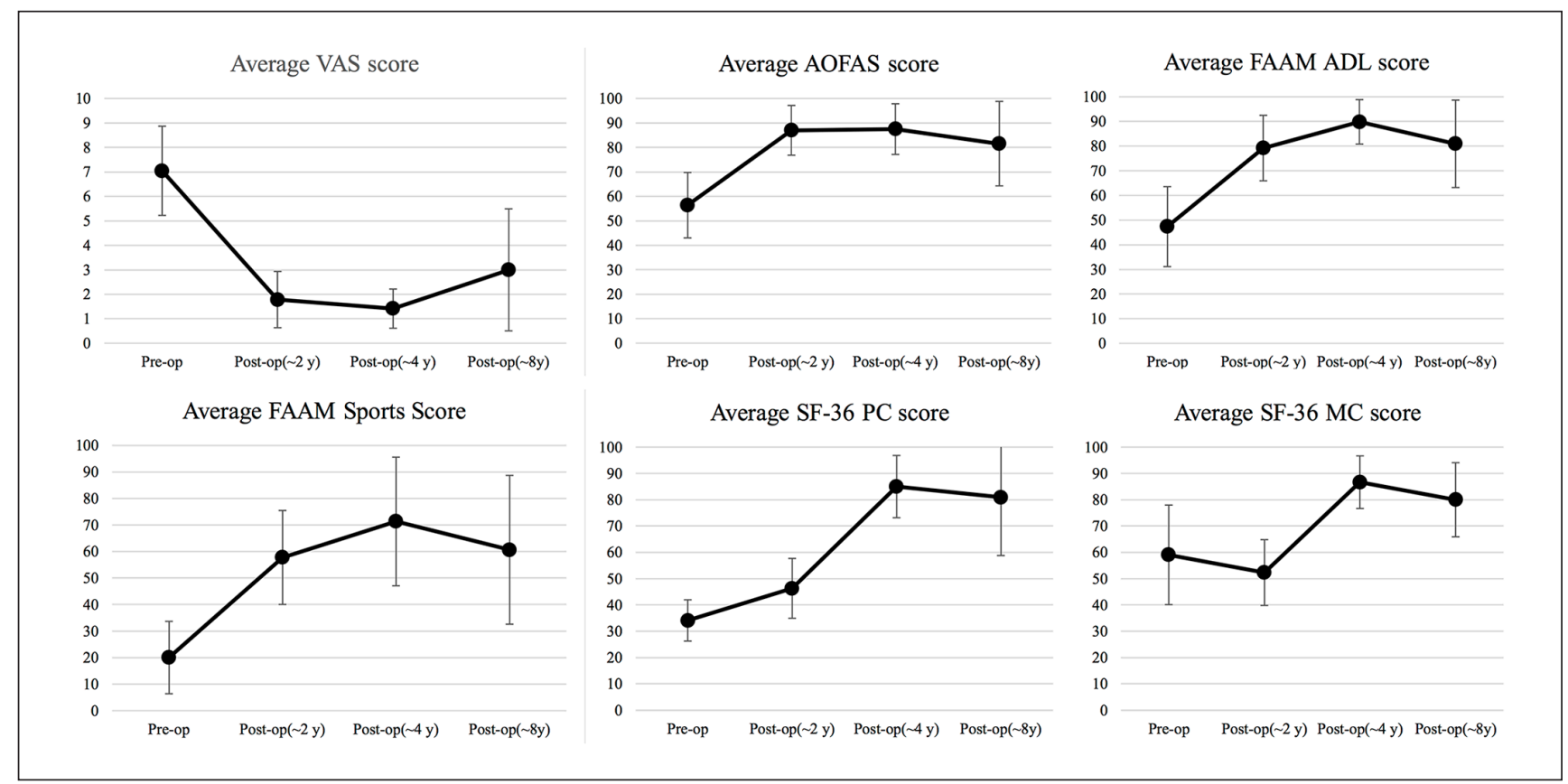

Figure 2. Long-term patient functional outcome scores assessed preoperatively and postoperatively at the 2-year, 4-year, and 8-year follow-up.

Additionally, another patient did show persistent pain within the first year after surgery, requiring second-look arthroscopy with debridement. On examination, the patient was noted to have partial delamination of the graft as shown in Figure 4. An osteochondral autograft transfer system was considered, but he eventually improved and opted out of 


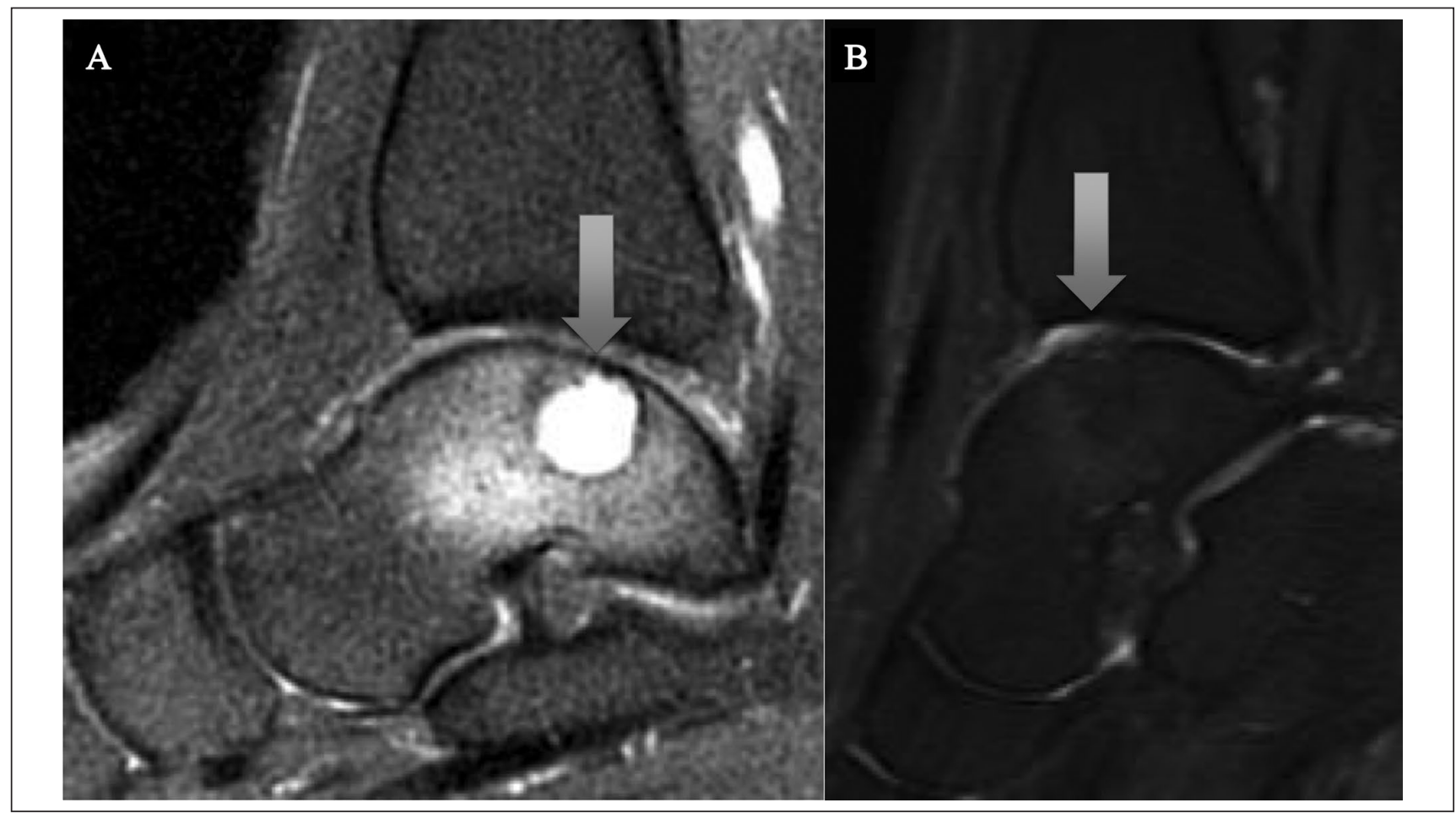

Figure 3. Magnetic resonance imaging (MRI) of same patient before and after operation. (A) Preoperative MRI of patient with a large osteochondral lesion of the talus, (B) postoperative MRI 2 years after particulated articular cartilage allograft transplantation.

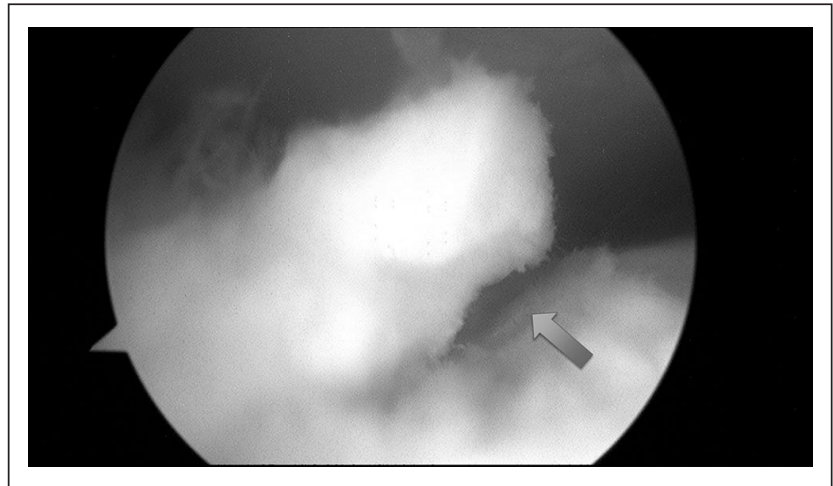

Figure 4. Second-look arthroscopy of patient I with persistent pain showing partial graft delamination.

additional operative intervention. There were no complications associated with calcaneal bone grafting.

\section{Discussion}

This small cohort study showed that the use of arthroscopyassisted particulated juvenile cartilage allograft implantation of talar osteochondral lesions is an effective single procedure treatment modality for the treatment of difficult to treat lesions, primarily moderate sized lesions or patients who failed microfracture. These results demonstrate clinically positive long-term outcomes for a cohort of patients followed over the course of 6-10 years, as assessed by patient-reported survey outcomes.

This study's findings showed comparable results to others who have analyzed OCLTs treated with allograft transplantion. ${ }^{9}, 10,19,26,30,45$ Bleazey et $\mathrm{al}^{9}$ followed a cohort of 7 patients 6 months after surgery, who demonstrated clinically significant improvements in self-reported pain and activity scale scores. Coetzee et a $\mathbf{l}^{17}$ followed a cohort of 24 patients for approximately 16 months and reported that $78 \%$ of patients had AOFAS scores demonstrating good to excellent scores. In this study, all patients achieved the MCID for the majority of PROMs assessed except for 2 patients, which had little to no improvement in their postoperative scores.

When analyzing patient outcome functional scores relative to different time points, there was a clinically significant (not statistically significant) peak at the 4-year mark relative to 8-year follow-up. This begs the question of if the longevity of the graft or its maximal benefits may reach a limit before patients decompensate again. This could be explored via MRI or second-look arthroscopy to observe continuous graft incorporation. It should be noted, however, that in vitro studies of osteochondral allograft incorporations have noted how allografts have significantly lower levels of cartilage proteoglycans along with depleted metalloproteinases compared with normal patient defective cartilage, which can in fact contribute to longer-term stability in vivo. ${ }^{20}$ Our participants' mildly 
worsening functionality and pain may therefore be better explained by surrounding tissue degradation, preclinical osteoarthritis, or an entirely separate, concomitant ligamentous or bone injury.

The findings of this study, overall, suggest that particulated juvenile articular cartilage allograft transplantation is a safe and effective treatment option. The one additional patient who did require second-look arthroscopy with debridement of the graft site did have improvement in terms of his symptoms and pain with functional and pain scores. For this particular patient, it raises the question of whether graft hypertrophy is also a potential problem with allograft cartilage implantation; second-look arthroscopy with debridement was also warranted for 7 of 33 patients in Heida et al's ${ }^{26}$ series, with at least 2 patients definitively noted for graft hypertrophy. As reported in the systematic analysis performed by Saltzman et $\mathrm{al},{ }^{45}$ revision to an open osteochondral allograft with medial malleolar osteotomy is infrequent, with only 1 reported in their review of 4 studies. The predominant reason for reoperation was hardware removal (medial malleolar osteotomy hardware). As far as this team is aware, no other studies to date have reported need for revision to osteochondral allograft.

In discussing graft incorporation, Saltzman et $\mathrm{al}^{45}$ reported excellent clinical outcomes in their relatively short-term follow-up, despite MRI-proven persistent subchondral edema and minimal change in lesion appearance up to 2 years postoperatively. They hypothesized that given the promising clinical results, the consolidation process may lag and take several years to show on advanced imaging. It is important to note that alternative treatments such as autologous chondrocyte implantation have shown integration on advanced imaging at up to 5 or 10 years postoperatively. ${ }^{23}$ Incorporation was observed by MRI at close to 2 years postoperatively for our 1 patient, which warranted additional imaging for a nonrelated ankle complaint (Figure 3).

Lesion size alone has been shown to correlate with clinical outcomes. A systematic review by Ramponi et $\mathrm{al}^{44}$ including 25 studies with 1868 ankles demonstrated the critical lesion size warranting BMS is for lesion sizes less than $107.4 \mathrm{~mm}^{2}$. Autologous chondrocyte implantation also has a recommended critical size limitation of less than 400 $\mathrm{mm}^{2}$. Notably, a recent study by Yasui et $\mathrm{a}^{56}$ showed that MRI often overestimated lesion size when compared to measurements found intraoperatively and should also be considered when deciding which modality to employ. In this report, patients with lesion sizes up to $260 \mathrm{~mm}^{2}$ achieved the MCID in the majority of scores assessed, suggesting improved outcomes.

Overall, several treatment options have been described for moderate-sized and/or difficult osteochondral lesions of the talus without a clear-cut consensus on the best treatment strategy. The hypothetical advantage to using juvenile allograft cartilage implantation is that it can be performed as a single-stage procedure that does not require harvesting the patient's own tissue, thereby obviating the risk of donor site complications. Furthermore, juvenile chondrocytes have been shown to produce more extracellular matrix proteins (GAGs), synthesize higher levels of type II collagen, and exist in a higher density in articular cartilage compared with adult chondrocytes., ${ }^{2,10,39}$ Additionally, it confers through its properties a chance to re-create hyaline cartilage through an arthroscopic procedure without the morbidity of an open surgery. ${ }^{11}$ Particulated juvenile articular cartilage allograft may also be a reliable treatment option in patients who have undergone previously failed microfracture. Although there may be a theoretical concern for fibrocartilage formation after a bone marrow stimulating treatment, all 4 patients in this study who had previous surgery had good to excellent outcomes, with only 1 requiring additional debridement.

Though many benefits of allograft transplantation have been discussed, this intervention is not without limitation. In addition to its expensive price and reduced availability in certain geographical regions, a recent systematic review by Aldawsari et $\mathrm{al}^{3}$ found in radiographic imaging, a lack of repair in subchondral bone and lamina in patients treated with juvenile allograft transplantation, with concomitant satisfactory functional outcome scores reported. This can imply that although patients achieve improved functional outcome scores after allograft transplantation, at the cellular level, full restoration of the normal hyaline articular cartilage is unlikely. Furthermore, for the 6 patients that had a concomitant calcaneus bone graft, donor site morbidity could present as a complication; nevertheless, reports are infrequent. O'Malley et $\mathrm{al}^{41}$ observed moderate to severe complications after percutaneous calcaneal autograft bone harvest in $1.4 \%(3 / 393)$ of patients, whereas knee donor-site morbidity for knee-ankle mosaicplasty has been cited at $17.2 \% .{ }^{4}$ Although these studies' methodology for grafting were not identical, harvesting using the calcaneal bone appears to be a reasonably safe option.

The strengths of this study include the use of a singlesurgeon cohort with a longer period of follow-up than any other institution has previously reported. This study also reports on a specific cohort of patients with poor prognostic factors. Contrarily, notable limitations include that population prospectively followed lacked 1:1 matching of patients to controls nor comparison to other interventions. Lesions were measured arthroscopically, which may not adequately describe the true lesion size given (1) how lesion edges are defined is not standardized and (2) lesion size likely is widened after debridement intervention. ${ }^{56}$ Additionally, several patients had concomitant procedures performed, which does not necessarily attribute all outcome measure values to the single allograft. Postoperative and long-term follow-up imaging was not obtained for 
most patients. Therefore, these results of patient-reported outcomes should not be extrapolated to suggest restoration of the defect nor can comment on the status of the cartilaginous tissue. The presence or absence of ankle arthritis also could not be commented on. Furthermore, 2 of 15 patients were lost to follow-up whereas assessment scores were predominantly self-reported by patients, which intrinsically presents reporting bias. The AOFAS score in particular has not been validated as a true outcome metric. To remove this subjectivity, a follow-up to the evaluation of this technique would perhaps involve imaging of all lesions to fully assess graft incorporation and evaluation for potential osteoarthritis. Several methodologies have been suggested in calculating the MCID with unclear differentiation in which is the most effective. A post hoc power analysis for each outcome of interest demonstrated a study power of at least $95 \%$. With such large effect sizes seen for all outcomes, the 13 patients were an adequate sample size to be sufficiently powered to detect a statistically significant difference from preoperative to last follow-up. Ultimately, a larger-scale randomized controlled trial is needed to validate this as a superior treatment option as well as to further elucidate the risk factors for failure.

\section{Conclusion}

Patients with high-risk OCLTs, a subgroup underexamined and characterized by inferior outcomes, remain a challenging clinical entity to treat successfully as is evident by the multitude of modalities used to manage this pathology. Although several operative options exist, these results suggest juvenile cartilage particulated allograft may be a favorable selection. Understanding the longevity of this intervention can better aid clinicians in deciding if this treatment option is appropriate for patients, while also financially pragmatic. In sum, our findings suggest allograft transplantation is an effective long-term treatment option for patients with talar osteochondral lesions and should be a part of the orthopedics' armamentarium.

\section{Declaration of Conflicting Interests}

The author(s) declared no potential conflicts of interest with respect to the research, authorship, and/or publication of this article. ICMJE forms for all authors are available online.

\section{Funding}

The author(s) received no financial support for the research, authorship, and/or publication of this article.

\section{ORCID iDs}

Artine Arzani, BS, iD https://orcid.org/0000-0003-4184-5256

Kshitij Manchanda, MD, iD https://orcid.org/0000-0002-1127-5312

\section{Supplemental Material}

A supplemental video for this article is available online.

\section{References}

1. Adams SB, Viens NA, Easley ME, Stinnett SS, Nunley JA. Midterm results of osteochondral lesions of the talar shoulder treated with fresh osteochondral allograft transplantation. $J$ Bone Joint Surg Am. 2011;93(7):648-654.

2. Adkisson HD, Martin JA, Amendola RL, et al. The potential of human allogeneic juvenile chondrocytes for restoration of articular cartilage. Am J Sports Med. 2010;38(7):13241333.

3. Aldawsari K, Alrabai HM, Sayed A, Alrashidi Y. Role of particulated juvenile cartilage allograft transplantation in osteochondral lesions of the talus: a systematic review. Foot Ankle Surg. 2021;27(1):10-14.

4. Andrade R, Vasta S, Pereira R, et al. Knee donor-site morbidity after mosaicplasty - a systematic review. J Exp Orthop. 2016;3(1):31.

5. Ankle Sprains in Children. Massachusetts General Hospital. https:/www.massgeneral.org/orthopaedics/children/conditions-and-treatments/ankle-sprains-children.

6. Bernstein JA, Mauger DT. The minimally clinically important difference (MCID): what difference does it make? $J$ Allergy Clin Immunol Pract. 2016;4(4):689-690.

7. Bexkens R, Ogink PT, Doornberg JN, et al. Donor-site morbidity after osteochondral autologous transplantation for osteochondritis dissecans of the capitellum: a systematic review and meta-analysis. Knee Surg Sports Traumatol Arthrosc. 2017;25(7):2237-2246.

8. Bisicchia S, Rosso F, Amendola A. Osteochondral allograft of the talus. Iowa Orthop J. 2014;34:30-37.

9. Bleazey S, Brigido SA. Reconstruction of complex osteochondral lesions of the talus with cylindrical sponge allograft and particulate juvenile cartilage graft: provisional results with a short-term follow-up. Foot Ankle Spec. 2012;5(5):300-305.

10. Bonasia DE, Martin JA, Marmotti A, et al. Cocultures of adult and juvenile chondrocytes compared with adult and juvenile chondral fragments: in vitro matrix production. Am J Sports Med. 2011;39(11):2355-2361.

11. Bonasia DE, Martin JA, Marmotti A, et al. The use of autologous adult, allogenic juvenile, and combined juvenile-adult cartilage fragments for the repair of chondral defects. Knee Surg Sports Traumatol Arthrosc. 2016;24(12):3988-3996.

12. Buckwalter JA, Mow VC, Ratcliffe A. Restoration of injured or degenerated articular cartilage. J Am Acad Orthop Surg. 1994;2(4):192-201.

13. Bull PE, Berlet GC, Canini C, Hyer CF. Rate of malunion following bi-plane chevron medial malleolar osteotomy. Foot Ankle Int. 2016;37(6):620-626.

14. Cerrato R. Particulated juvenile articular cartilage allograft transplantation for osteochondral lesions of the talus. Foot Ankle Clin. 2013;18(1):79-87.

15. Chew KT, Tay E, Shuen Wong Y. Osteochondral lesions of the talus. Ann Acad Med. 2008;37(1):63.

16. Choi WJ, Jo J, Lee JW. Osteochondral lesion of the talus: prognostic factors affecting the clinical outcome after 
arthroscopic marrow stimulation technique. Foot Ankle Clin. 2013;18(1):67-78.

17. Coetzee JC, Giza E, Schon LC, et al. Treatment of osteochondral lesions of the talus with particulated juvenile cartilage. Foot Ankle Int. 2013;34(9):1205-1211.

18. D’Ambrosi R, Maccario C, Serra N, Ursino C, Usuelli FG. Relationship between symptomatic osteochondral lesions of the talus and quality of life, body mass index, age, size and anatomic location. Foot Ankle Surg. 2018;24(4):365-372.

19. Dekker TJ, Steele JR, Federer AE, Easley ME, Hamid KS, Adams SB. Efficacy of particulated juvenile cartilage allograft transplantation for osteochondral lesions of the talus. Foot Ankle Int. 2018;39(3):278-283.

20. Ding L, Zampogna B, Vasta S, et al. Why do osteochondral allografts survive? Am J Sports Med. 2015;43(10):2459-2468.

21. Farr J, Yao JQ. Chondral defect repair with particulated juvenile cartilage allograft. Cartilage. 2011;2(4):346-353.

22. Frank RM, Cotter EJ, Nassar I, Cole B. Failure of bone marrow stimulation techniques. Sports Med Arthrosc. 2017;25(1):2-9.

23. Giannini S, Battaglia M, Buda R, Cavallo M, Ruffilli A, Vannini F. Surgical treatment of osteochondral lesions of the talus by open-field autologuous chondrocyte implantation: a 10-year follow-up clinical and magnetic resonance imaging T2-mapping evaluation. Am J Sports Med. 2009;37(1 suppl):112S-118S.

24. Gross CE, Adams SB, Easley ME, Nunley JA. Role of fresh osteochondral allografts for large talar osteochondral lesions. J Am Acad Orthop Surg. 2016;24(1):e9-e17.

25. Grossman JP, Lyons MC. A review of osteochondral lesions of the talus. Clin Podiatr Med Surg. 2009;26(2):205-226.

26. Heida KA, Tihista MC, Kusnezov NA, Dunn JC, Orr JD. Outcomes and predictors of postoperative pain improvement following particulated juvenile cartilage allograft transplant for osteochondral lesions of the talus. Foot Ankle Int. 2020;41(5):572-581.

27. Hintermann B, Boss A, Schäfer D. Arthroscopic findings in patients with chronic ankle instability. Am J Sports Med. 2002;30(3):402-409.

28. Kannus P, Renstrom P. Treatment for acute tears of the lateral ligaments of the ankle. Operation, cast, or early controlled mobilization. J Bone Joint Surg Am. 1991;73(2):305-312.

29. Kraeutler MJ, Chahla J, Dean CS, et al. Current concepts review update: osteochondral lesions of the talus. Foot Ankle Int. 2017;38(3):331-342.

30. Kruse DL, Ng A, Paden M, Stone PA. Arthroscopic De Novo NT ${ }^{\circledR}$ juvenile allograft cartilage implantation in the talus: a case presentation. J Foot Ankle Surg. 2012;51(2):218-221.

31. Laffenêtre O. Osteochondral lesions of the talus: current concept. Orthop Traumatol Surg Res. 2010;96(5):554-566.

32. LaPrade RF, Botker JC. Donor-site morbidity after osteochondral autograft transfer procedures. Arthroscopy. 2004;20(7):e69-e73.

33. Lee M, Kwon JW, Choi WJ, Lee JW. Comparison of outcomes for osteochondral lesions of the talus with and without chronic lateral ankle instability. Foot Ankle Int. 2015;36(9):1050-1057.

34. Lindholm TS, Osterman K, Vankka E. Osteochondritis dissecans of elbow, ankle and hip: a comparison survey. Clin Orthop Relat Res. 1980;148:245-253.
35. Looze CA, Capo J, Ryan MK, et al. Evaluation and management of osteochondral lesions of the talus. Cartilage. 2017;8(1):19-30.

36. McNickle AG, Provencher MT, Cole BJ. Overview of existing cartilage repair technology. Sports Med Arthrosc. 2008;16(4):196-201.

37. Murawski CD, Foo LF, Kennedy JG. A review of arthroscopic bone marrow stimulation techniques of the talus: the good, the bad, and the causes for concern. Cartilage. 2010;1(2): 137-144.

38. Nam EK, Ferkel RD, Applegate GR. Autologous chondrocyte implantation of the ankle: a 2- to 5-year follow-up. Am J Sports Med. 2009;37(2):274-284.

39. Namba RS, Meuli M, Sullivan KM, Le AX, Adzick NS. Spontaneous repair of superficial defects in articular cartilage in a fetal lamb model. J Bone Joint Surg Am. 1998;80(1):4-10.

40. O'Loughlin PF, Heyworth BE, Kennedy JG. Current concepts in the diagnosis and treatment of osteochondral lesions of the ankle. Am J Sports Med. 2010;38(2): 392-404

41. O’Malley MJ, Sayres SC, Saleem O, et al. Morbidity and complications following percutaneous calcaneal autograft bone harvest. Foot Ankle Int. 2014;35(1):30-37.

42. Orr JD, Dawson LK, Garcia EJ, Kirk KL. Incidence of osteochondral lesions of the talus in the United States military. Foot Ankle Int. 2011;32(10):948-954.

43. The Use of Osteochondral Transplantation for the Treatment of Osteochondral Lesions of the Talus Position Statement. American Orthopaedic Foot \& Ankle Society; 2018:1-5. https:// www.aofas.org/docs/default-source/research-and-policy/osteochondral-lesions-position-statement.pdf?sfvrsn=95e8c93b_2.

44. Ramponi L, Yasui Y, Murawski CD, et al. Lesion size is a predictor of clinical outcomes after bone marrow stimulation for osteochondral lesions of the talus: a systematic review. Am J Sports Med. 2017;45(7):1698-1705.

45. Saltzman BM, Lin J, Lee S. Particulated juvenile articular cartilage allograft transplantation for osteochondral talar lesions. Cartilage. 2017;8(1):61-72.

46. Savage-Elliott I, Ross KA, Smyth NA, Murawski CD, Kennedy JG. Osteochondral lesions of the talus: a current concepts review and evidence-based treatment paradigm. Foot Ankle Spec. 2014;7(5):414-422.

47. Saxena A, Eakin C. Articular talar injuries in athletes: results of microfracture and autogenous bone graft. Am J Sports Med. 2007;35(10):1680-1687.

48. Schachter AK, Chen AL, Reddy PD, Tejwani NC. Osteochondral lesions of the talus. J Am Acad Orthop Surg. 2005;13(3):152-158.

49. Steadman JR, Rodkey WG, Briggs KK. Microfracture: its history and experience of the developing surgeon. Cartilage. 2010;1(2):78-86.

50. Van Bergen CJA, Tuijthof GJM, Sierevelt IN, Van Dijk CN. Direction of the oblique medial malleolar osteotomy for exposure of the talus. Arch Orthop Trauma Surg. 2011;131(7): 893-901.

51. van Dijk CN, Reilingh ML, Zengerink M, van Bergen CJA. Osteochondral defects in the ankle: why painful? Knee Surg Sports Traumatol Arthrosc. 2010;18(5):570-580.

52. VanTienderen RJ, Dunn JC, Kusnezov N, Orr JD. Osteochondral allograft transfer for treatment of osteochondral 
lesions of the talus: a systematic review. Arthroscopy. 2017; 33:217-222.

53. Verhagen RAW, Struijs PAA, Bossuyt PMM, Van Dijk CN. Systematic review of treatment strategies for osteochondral defects of the talar dome. Foot Ankle Clin. 2003;8(2): 233-242.

54. Wright A, Hannon J, Hegedus EJ, Kavchak AE. Clinimetrics corner: a closer look at the minimal clinically important difference (MCID). J Man Manip Ther. 2012;20(3): 160-166.

55. Yang HY, Lee KB. Arthroscopic microfracture for osteochondral lesions of the talus: second-look arthroscopic and magnetic resonance analysis of cartilage repair tissue outcomes. J Bone Joint Surg Am. 2020;102(1):10-20.
56. Yasui Y, Hannon CP, Fraser EJ, et al. Lesion size measured on MRI does not accurately reflect arthroscopic measurement in talar osteochondral lesions. Orthop J Sports Med. 2019; 7(2):2325967118825261.

57. Yoshimura I, Kanazawa K, Takeyama A, et al. Arthroscopic bone marrow stimulation techniques for osteochondral lesions of the talus: prognostic factors for small lesions. Am J Sports Med. 2013;41(3):528-534.

58. Zanon G, Di Vico G, Marullo M. Osteochondritis dissecans of the talus. Joints. 2014;2(3):115-123.

59. Zengerink M, Struijs PAA, Tol JL, van Dijk CN. Treatment of osteochondral lesions of the talus: a systematic review. Knee Surg Sports Traumatol Arthrosc. 2010;18(2): 238-246. 